ARTICLE

\title{
'Find a sport and carry on': Posttraumatic growth and achievement in British Paralympic athletes
}

\author{
Hanna Kampman · Kate Hefferon
}

\begin{abstract}
Background: The negative aftermath of acquired disability has been studied rigorously. The research on achievement and success after an acquired disability is still in its infancy, and more research is needed on the positive psychological outcomes that may arise as a result of surviving and dealing with trauma. Objective: This study aimed to provide an in-depth account of the experience of acquired disability, engagement in elite sport and Posttraumatic Growth in Paralympic athletes. Method: Three self-selected athletes (two females, one male) from Great Britain's 2012 Paralympic team were interviewed using semi-structured techniques. The interviews were recorded, and the data was transcribed. Data were analysed using Interpretative Phenomenological Analysis (IPA). Results: The study identified that for these athletes, sport was a fundamental route to experiencing posttraumatic growth (PTG). Sport was perceived to be a platform of recovery, camaraderie, achievements and the basis for a new identity as an athlete. Furthermore, the team was seen as a resource, creating a safe environment in which to learn new skills, share practical ideas and promote a sense of equality. Additionally, the role of the body in facilitating PTG was central to these individuals' experiences. Considerations of these findings as well as suggestions for future research are discussed.
\end{abstract}

Keywords: Acquired disability, Paralympic athlete, posttraumatic growth, sports, body

\section{Introduction}

The aim of this study was to provide an in-depth account of the experience of engaging in elite sport after acquiring a physical impairment that led to disability. Particularly, this study focused on exploring the experience of Posttraumatic Growth (PTG) in Paralympic athletes who participated in what was the largest Paralympic games in London 2012. This niche population of top-level athletes was recruited to elicit rich, meaningful data about these athletes' lived experiences. Alongside researching challenges, this study aimed to understand individuals who were reporting positive psychological and physical changes due to their experience of dealing with the aftermath of physical impairment. Thus, interviewing elite athletes, who have competed at one of the most prestigious and respected competitions in their field, can bring valuable insight into the experience of PTG within the sporting context. This contribution to the area of sport and 
positive psychology has implications for rehabilitation practices as well as the facilitation of peak performance in elite sports.

Furthermore, the study will bring much needed knowledge around the role of the body within PTG following acquired disabilities.

\section{Literature review}

From a historical perspective, 'disability has not been conceptualized within the context of strengths and positive attributes' (Wehmeyer, 2014, p. 3). More specifically, research on acquired disability has traditionally taken a pathological approach to examine the way it affects an individual, with depression cited as one of the most researched psychological states (Elliott \& Kennedy, 2004; Lucas, 2007a, 2007b). A severe injury, such as acquired disability, can be seen as a traumatic stressor, and can lead to significant disruption in one's life and psychological wellbeing (Desmond, Coffey, Gallagher, MacLachlan, Wegener and O'Keeffe, 2012; Vanlandewijck \& Thompson, 2011). Subsequently, an individual must deal with changes in the functionality of their physical self, or even losing a body part(s), potentially leading to changes in one's body and self-image (Desmond et al., 2012; Sparkes \& Smith, 2013). Various other corporeal changes may also occur, such as losing physical comfort, changes in mobility, and lacking vitality. Furthermore, the capability to carry out various activities might be challenged or become no longer possible (Marini \& Stebnicki, 2012; Vanlandewijck \& Thompson, 2011).

In addition to these personal and physical changes, an individual's social position may be challenged (Wright, 1983), such that people with acquired disabilities may be 'looked upon, identified, judged and represented primarily through their bodies, which are perceived in popular consciousness to be imperfect, incomplete and inadequate' (Hargreaves, 2001, p. 185). For this very reason, physical trauma can be distressing, as it challenges not only the person's perception of themselves but additionally how others perceive them (Vanlandewijck \& Thompson, 2011; Wright, 1983). Indeed, Charmaz (1995a) suggests that visible (physical) disability can produce a 'master status' and 'master identity' (p. 277) for the individual, overpowering every other status or identity that the person possesses (Charmaz, 1995a; Charmaz, 1995b).

Although the majority of the trauma research in this area has been devoted to understanding how one copes with the negative physical and psychological consequences of physical trauma (Ivtzan, Lomas, Hefferon \& Worth, 2015; Wehmeyer, 2014), recent research has started to look beyond coping and survival, to focus more on the positive outcomes that individuals may report after surviving a trauma (Dunn, Uswatte, Elliot, Lastres \& Beard, 2014; Dunn, Uswatte, \& Elliott, 2009; Griffiths \& Kennedy, 2012; Joseph, 2012; Kampman, Hefferon, Wilson \& Beale, 2015; Tedeschi \& Calhoun, 1996; 2004; Tedeschi, Park, \& Calhoun, 1998; Tedeschi, Shakespeare-Finch, Taku, \& Calhoun, 2018). Broadly termed within the psychological literature as 'adversarial growth' (Joseph \& Linley, 2004; Ivtzan et al., 2015), arguably the most dominant construct studied within this literature is Posttraumatic growth (PTG), which is defined as 'the experience of positive change that the individual experiences as a result of the struggle with a traumatic event' (Calhoun \& Tedeschi, 2013, p. 6). Posttraumatic growth is positioned as both a process and outcome, with differing perspectives regarding what types of changes these may be (e.g. from cognitive to behavioural) (Tedeschi, Shakespeare-Finch, Taku \& Calhoun, 2018; Hobfoll, Hall, Canetti-Nisim, Galea, Johnson \& Palmieri, 2007). The main model of PTG posits that growth typically manifests in five different domains: enhanced appreciation for life, increased 
interpersonal relationships, feeling a sense of personal strength, finding new possibilities and spiritual/existential development (Tedeschi, Cann, Taku, Senol-Durak, \& Calhoun, 2017). Overall, the experience of PTG is personal and while some individuals may experience it across one or all five domains, others might not experience PTG at all (Tedeschi \& Calhoun, 1996; Tedeschi \& Calhoun, 2004; Tedeschi et al., 1998). Additionally, PTG can often co-exist with distress and is not a signifier that one is necessarily "happy".

Over the past decade, the research area into PTG has grown, and work continues to explore the intricacies, caveats and contradictions regarding this construct (please see Ivtzan et al., 2015; Jayawickreme \& Blackie, 2014). One topic area that has been argued to have received limited attention within the main theories and models of PTG is that of corporeality; the role of the body as both part of the process and as a PTG outcome (Hefferon, Grealy \& Mutrie, 2008; 2009; 2010; Hefferon, 2012; 2013). Building on earlier philosophical work of Merleau-Ponty (2003), Frank (1995/2013) and Leder (1990), and deriving from qualitative work with illness populations (Hefferon et al., 2008; 2009; 2010), Hefferon $(2012 ; 2013)$ proposed that the body was an integral part of the PTG process within traumas where the body has been threatened, damaged or altered (Hefferon, 2009; 2010). Extending this into acquired disability, Kampman, Hefferon, Wilson and Beale (2015) found that the post-traumatic growth experiences of people who had been severely injured had trauma-specific elements as well as unique corporeal features due to the 'direct and substantial impact on the body' (p.292). The proposition that different trauma types and contexts may result in different PTG processes aligns with current researchers who are exploring the nuances that trauma dynamics can influence on the PTG journey (Shakespeare-Finch \& Armstrong, 2010; Karanci, et al., 2012; Kira, Aboumediene, Ashby, Odenat, Mohanesh \& Alamia, 2013; Kılıç, Magruder \& Koryürek, 2016; Shuwiekh, Kira \& Ashby, 2018; Chopko, Palmieri \& Adams, 2018; Wu, Kaminga, Dai, Deng, Wang, Pan \& Liu, 2019). Thus, the working theory of Corporeal PTG (C-PTG) (Hefferon, 2012) posits that physical trauma, where the body is permanently affected, either by an internal or external transgressor, can lead to a heightened corporeal awareness, bringing attention to the corporeal self. Indeed, the body is a known reminder of our mortality (e.g. mortality salient environment; Grabe, Cook, Routledge, Anderson \& Arndt, 2005; Goldenberg et al., 2001; Cordova, 2008) and thus engaging with this enhanced corporeal existential awareness can prompt an individual to renegotiate this new corporeal bodyself relationship. This new relationship with the body may also lead to examples of actionfocused growth (Hobfall et al., 2007) via positive changes in health behaviours such as self-care activities (e.g. listen to the body; be kinder to the body) and the uptake of physical activity and sport. Recent research has offered preliminary supportive evidence for the working theory of CPTG within breast cancer survivors (Gorven \& du Plessis, 2018) and extended current PTG measurement tools for the inclusion of more corporeal elements of the PTG process (Physical PTG scale; Walsh, Groarke, Morrison, Durkan, Rogers \& Sullivan, 2018; Walsh, Morrison, Conway, Rogers, Sullivan \& Groarke, 2018). To date, the role of the body in the PTG process and as outcome has focused primarily within illness populations and has not yet been explored within acquired disability.

\section{Adapted sport and society}

The body - especially the sporting body - is indeed central to the study of Paralympians. DePauw (1997) stated that 'it is important to understand our attitudes towards the body and our view of the body because this view will define how we view disability and 
people with disabilities' (p.420). Individuals with impairments are often defined within the medical model of disability, where the 'issue' of impairment or disability is located 'within the individual' (Oliver 1996, as cited in Hargreaves, 2001, p.178). This implies that problems, whether psychological or functional, arise from the impairment itself. This view is challenged by the social model of disability which argues that these problems are located within society (Hargreaves, 2001; Howe, 2011), arguing that it is society that fails to support the needs of individuals with impairments or disabilities. This model shifts the thinking away from the idea that something is wrong with one's body and asks the question 'what is wrong with society'? and aims to tackle 'disabling social, environmental and attitudinal barriers' (Hargreaves, 2001, p.179). Adapted sport can be one example of this, where the disabling social, environmental and attitudinal barriers are partly removed to enable a level playing field and access to participation (Howe, 2011). However, this environment is not without its problems (Caddick \& Smith, 2014) and the issues of classification based on the level of impairment rather than functionality are currently debated ${ }^{1}$.

The original idea of the International Paralympic Movement was to promote social reintegration (Brittain, 2010). The term 'Paralympic' is often incorrectly thought to refer to paraplegia. However, it refers to Greek preposition 'para', meaning 'next to' or 'parallel to' Olympic Games (Brittain, 2010). Today, the Paralympic Games are the second largest sporting event in the world after the Olympics, and adapted sports, in general, are gaining political attention and receiving more recognition from the media (Brittain, 2010; Vanlandewijck \& Thompson, 2011). For example, the Invictus Games, which is a multisport event for veterans and service members who have endured illnesses and injuries, was given 12 hours of coverage by BBC in the UK, suggesting that the interest for these events is on the rise (Shirazipour, Meehan \& Latimer-Cheung, 2017). Furthermore, there are several additional national and international competitions such as Disability World Cups and Championships, Special Olympic World Games, Deaflympics, IBSA World Championship and Games, Parapan American Games, Asian Para Game and Paralympic World Cup (Disability Sport, 2014), evidencing the significant need and opportunity to understand the role of elite sports in these athletes' lives.

\section{Physical activity, psychological wellbeing and growth}

In general, the evidence supporting the positive association between physical activity and psychological well-being is growing (Acevedo, 2012; Biddle, Mutrie \& Gorely, 2015; Fox, Biddle, \& Boutcher, 2001; Taylor et al., 2004; Wankel \& Berger, 1990; Faulkner, Hefferon \& Mutrie, 2015). Although physical activity is not currently mentioned in any of the main academic models of wellbeing (please see Lambert, D'Cruz, Schlatter \& Barron, 2016 for review), decades of research has consistently shown that participating in physical activity has been associated among the general population with improved

\footnotetext{
${ }^{1}$ These discussions are beyond the scope of this paper, however, it is important to note in order to keep a critical eye towards sport participation overall (Caddick \& Smith, 2014).
} 
mood, reduction of stress levels, as well as improved positive self-concept, and these benefits might even be higher in clinical populations (Penedo \& Dahn, 2005; Wankel \& Berger, 1990; Biddle, Mutrie \& Gorely, 2015). There is further evidence that exercise can enhance body image, self-confidence and self-efficacy as well as overall psychological well-being (Alleva, Martijn, Van Breukelen, Jansen, \& Karos, 2015; Menzel \& Levine, 2011; Martin Ginis, Bassett-Gunter, \& Conlin, 2012; Ryff \& Keyes, 1995). Conversely, inactivity is strongly correlated with psychological issues such as stress, anxiety and depression (Faulkner \& Taylor, 2005; Lambert et al., 2016).

Furthermore, engaging in physical activity has been linked to the facilitation and as an outcome of posttraumatic growth for those that have experienced physical trauma (Sabiston, McDonough \& Crocker, 2007; Hefferon et al., 2008; 2009; 2010; Hefferon, 2012; 2018a; Kampman et al., 2015; Crawford, Gayman \& Tracey, 2014; Day, 2013; Day \& Wadey, 2016). More specifically, Day (2013) found that sport helped athletes to recognise possibilities in their lives, accept limitations and noted heightened sense of responsibility around their choices in life as well as higher levels of meaning. Crawford et al. (2014) also interviewed athletes who had acquired spinal cord injury (SCI). In this population, sport was reported as an essential part to process their injury and identity. Athletes conveyed appreciating life more as well as gaining clarity and perspective. They also reported not taking things for granted anymore. Other benefits included: finding new skills, increased problem-solving skills and mental toughness as well as being less judgemental. Additionally, Day and Wadey (2016) found that according to the two male athletes interviewed, high levels of sport provided mastery experiences, enhanced relationships, enhanced corporeal understanding and improved life philosophies. More recently, Hammer and colleagues (2019) interviewed 14 purposefully sampled triathlon athletes reporting PTG and found that sport provided meaningful social benefits and a sense of community. Specifically, through sports, individuals gained friendships, opportunities to learn from others, a sense of empowerment and control as well as competence (Hammer, Podlog, Wadey, Galli, Forber-Pratt, Newton, Hall \& Greviskes, 2019).

Due to the potential that sport and exercise appear to have in facilitating psychological growth following adversity and trauma, this study aimed to investigate the experience of posttraumatic growth and the transition from amateur to elite level athletics, following acquired disability, offering unique insight into how acquired disability led to engagement and training in elite sports and eventually the 2012 Paralympics in London. The study also aimed to understand the role of societal influences on the growth process and identity as an elite athlete. Furthermore, the study aims to give voice to an underrepresented participant pool, a unique set of elite athletes at the very highest level of the adapted sports participation, who have not been adequately represented in the posttraumatic growth research thus far. Finally, as researchers have also called for more embodied approaches to understanding growth following adversity within the context of sport (Day \& Wadey, 2017) this study aimed to understand of the role of the body in 
the process and as an outcome of PTG, following acquired disability as this topic has primarily been explored within illness populations.

\section{Methods}

\section{Methodological paradigm}

To date, there has been a dearth of qualitative research within posttraumatic growth and positive psychological inquiry (Hefferon, Ashfield, Synard \& Waters, 2017; Hefferon, 2018b; Tedeschi et al., 2018). This study thus aimed to explore the topic of Posttraumatic growth, within British Paralympic athletes, beyond the quantitative designs typically employed by the research area. More specifically, Interpretative Phenomenological Analysis (IPA) was chosen as its in-depth exploratory nature enables researchers the ability to study meaning in individual's experience, particularly meaning of injury (or illness) in one's life (Reid, Flowers, \& Larkin, 2005; Smith, Larkin, \& Flowers, 2009; Smith, 2017). IPA is typically used when the participant pool is very niche and hard to reach, due to access issues as well as restricted inclusion criteria. Furthermore, IPA was deemed an appropriate approach for this particular study as its theoretical origins are in phenomenological philosophy thus respecting the role of the body in perception and human experience (Carman, 2000; Smith et al., 2009). For example, Merleau-Ponty (2003) claimed that people know the world through their bodies, such that consciousness and the perceiving body are intertwined, not separate entities (Carman, 2000). In this specific study, the body is central to these individuals' stories, and thus IPA was an ideal methodology to study the meaning of the body in the experiences of these individuals.

\section{Participants}

The study inclusion criteria stipulated that athletes must have experienced previous trauma with severe physical injury or illness after birth and participated in the 2012 Paralympics in London. The participants were three Paralympic athletes (two females and one male) who had self-identified as having experienced Posttraumatic Growth. All had been involved with team sports for 2-3 years, were under 35 years old and single at the time of the interviews. Disability levels varied from below-knee amputations to severe injury to a limb. These injuries had happened 4-7 years prior to the interviews. The inclusion criteria stipulated that time since their injury had to be more than 1 year when participating in the study.

Due to IPA's in-depth exploratory nature, three to six participants has been deemed an optimal range to perform an IPA analysis of the participants' experiences (Smith et al. 2009). The use of a small sample of three participants is valid in this study for several reasons. First of all, the number adheres to the methodology's underlying philosophical assumptions of Idiography; utilising a small, homogeneous sample to produce rich, meaningful data about a persons lived experience (Smith, 2017). These small, idiographic sample sizes are argued to contribute to research in several ways: to investigate areas of research that have not yet been explored; to access difficult to reach participants whose 
voices have not yet been represented in the literature and to compare and contrast these samples experiences in light of the existing research (Smith et al., 2009). Larger samples would essentially violate the philosophical assumptions that underpin IPA and arguably lower the quality and impact of the data produced (Smith, 2011). IPA advocates quality not quantity, with preferences for usage within case studies $(\mathrm{n}=1)$ (for papers with similar sample sizes, please see Eatough \& Smith, 2006; Bramley \& Eatough, 2005; Nizza, Smith \& Kirkham, 2018; Hartie \& Smith, 2016; Perridge, Hefferon, Lomas \& Ivtzan, 2017). Although published pieces tend range from single case studies to larger samples $(>10)$ (see Smith, 2011 for a review of quality in published IPA studies), utilising a number of 3-6 should provide 'meaningful points of similarity and differences between participants but not so many that one is in danger of being overwhelmed by the amount of data generated' (Smith et al., 2009, p.51). In addition, the larger the sample, the less detailed one can be in the analyses, with smaller samples producing a more detailed individual case analyses and then group analyses, privileging the individual throughout. Following on from this, writing up an IPA piece presents issues when employing larger sample sizes as individual voices can get lost from the results due to too many participants and not enough space to do the data justice (Smith, 2011). Finally, the data produced can arguably offer 'theoretical transferability' which argues that, 'the specifics are unique, but they are hung on what is shared and communal' (Smith et al., 2009, p. 38). In sum, IPA, and its idiographic approach, can offer positive psychologists the opportunity to explore the phenomena that we are interested in at a very intricate and in-depth level (Smith, 2017).

\section{Procedure}

Ethical approval was granted from the University of East London. Additionally, the Paralympic team's psychologist reviewed the research proposal and granted approval to proceed. The invitation and information sheet were sent to potential participants via the help of the development officer in England in the participants' respective sports. Three athletes agreed to be interviewed and met in a public place to conduct the interviews. Athletes were asked to read the information sheet and sign the consent forms which described the purpose of this research, individuals right to withdraw from the study at any time, and further information regarding the data handling after the interviews. The participants took part in one semi-structured interview, which used open-ended questions that were designed to bring further understanding to the research question while allowing the participants to take the interview to the direction that was important and central to their experience. Interviews lasted from 35 minutes to 65 minutes, after which participants were debriefed.

\section{Data Analysis}

The analysis was conducted using IPA to understand and make sense of the individual's subjective experience. IPA is an interpretative approach; thus, the interviews were conducted, transcribed and analysed by the $1^{\text {st }}$ author to ensure in-depth examination and understanding of each participant's experiences. The process of IPA asks the 
researcher to transcribe, read and re-read the transcription after which the initial exploratory coding is performed. The researcher noted descriptive, linguistic and conceptual elements within the transcripts. Once this had been completed, the researcher started to look for emergent themes. Themes were then grouped and searched for connections between the themes. This rigorous process was repeated with all the transcriptions after which the researcher started to search for connections between the themes across the participants to form master themes that describe these individuals' experiences most. To ensure validity and rigour within the analytic process, the $1^{\text {st }}$ author engaged in regular discussions with the second author (an expert in both IPA and PTG) regarding theme development. ${ }^{2}$

\section{Results and Discussion}

Three master themes emerged from the analysis - all with several subthemes - that yielded the experience of PTG and were voiced among all the participants (see Table 1). However, this experience was a journey where distress and posttraumatic growth coexisted. In addition to the original trauma, it was the dealing with the aftermath of the trauma that was perceived to promote PTG. The three main themes included: 1) Seeing opportunities instead of disabilities, 2) Sport was, Sport is \& Sport will be, and 3) The journey of the wounded body (See table 1). These themes will be discussed in the following section and connected to extracts from the transcripts. Overall, the analysis revealed a raw description of the lives of these individuals, without hiding the apparent obstacles that came with the acquired disability, whilst also showing the nature of thriving with an acquired disability.

Table 1.

\section{Master themes and subordinate themes and prevalence}

\begin{tabular}{|c|c|c|}
\hline Master themes & Subordinate themes & Prevalence \\
\hline \multirow{3}{*}{$\begin{array}{l}\text { 1. Seeing opportunities } \\
\text { instead of disabilities }\end{array}$} & 1.1 Merging the old life into the new one & $3 / 3$ \\
\hline & $\begin{array}{l}\text { Trauma and amputation enabling } \\
\text { opportunities }\end{array}$ & $2 / 3$ \\
\hline & 1.3 Paralympics 2012 changing the attitudes & $3 / 3$ \\
\hline \multirow{3}{*}{$\begin{array}{l}\text { 2. Sport was, Sport is \& } \\
\text { Sport will be }\end{array}$} & 2.1 "I am an Athlete" & $3 / 3$ \\
\hline & 2.2 Team as a resource & $3 / 3$ \\
\hline & 2.3 Being equal $\sim$ Feeling equal & $2 / 3$ \\
\hline \multirow{3}{*}{$\begin{array}{l}\text { 3. The journey of the } \\
\text { wounded body }\end{array}$} & $\begin{array}{l}\text { 3.1 Frustration towards the new body, missing } \\
\text { the old body }\end{array}$ & $3 / 3$ \\
\hline & 3.2 Rediscovering the body & $3 / 3$ \\
\hline & 3.3 Appreciating the new body & $3 / 3$ \\
\hline
\end{tabular}

\footnotetext{
2 Please see 'Assessing Validity' section within the conclusion for further elaboration on how quality was adhered to throughout the study.
} 


\section{Seeing opportunities instead of disabilities}

Among all the participants, it was clear that their disability was just one aspect of their life, and did not define their life altogether. In general, there was a very strong experience among the participants to 'get on with things' after the acquired disability. All of the athletes pointed out several positive aspects in their life that they believed would not have happened if the trauma had not occurred, such as new opportunities relating to disability, appreciating life more, becoming an athlete and participating in the Paralympics. These are all well-documented aspects of PTG in the literature (Joseph, 2012; Tedeschi \& Calhoun, 2004; Tedeschi et al., 1998).

\subsection{Merging the old life into the new one}

All of the participants here had to give up some aspects of their lives due to the trauma, and some had to change the direction of their life altogether (e.g. losing a job, hobby). Nevertheless, all of them found ways to incorporate their old life in some way into the new one; and often it was through sports. Here Anthony describes how he wanted to do something familiar from his life before the accident:

"I did a lot of sport before. I just wanted to do sports again, so it's just a sort of return... not returning to what I used to do, but doing the same sort of thing, so it's like carrying on you know in the same sort of thing." (Anthony)

And again, to further emphasise this, Anthony says:

"Yeah, I think it was just because I've always done it. You know, since I was a kid I always played sports you know football, swimming, rugby. When I was a kid. As I got older all I did was play rugby and ever since I can remember it was you know training two or three times a week, going to the gym you know, playing on a weekend and I've always done it. I just wanted to do that again, so just you know, get back to training doing something just because I've done it before. I don't think it necessarily was important what sport it was it was just-just the fact that I've done it before and I wanted to do -do it again." (Anthony)

Anthony's reasoning for doing sports again implies that it was important for him to find and do something familiar amongst all the changes. He seems to be illustrating the significance of sports in his life by saying that it was 'all he did'. This strong description illuminates the role that sports appear to have in his life, giving the sense that without sports there would be nothing left to do; 'all would be gone'.

Merging the old life into the new one through searching for new opportunities was an essential aspect of the PTG journey for these individuals. Similar findings have been reported in other qualitative studies as well as the positive psychological outcomes that can emerge by the continuation of pursuing one's goals and values despite the effects of the injury (Dunn et al., 2009; Griffiths \& Kennedy, 2012). These finding also support the 
previous finding from Day (2013) where sport helped athletes with disabilities to connect their pre-trauma life to the existing one, thus creating meaning. Furthermore, Crawford et al. (2014) found that having goals in sport connected to motivation and were a source of self-confidence for athletes with Spinal cord injury.

\subsection{Trauma and amputation enabling possibilities}

Despite also describing some of the negative life-altering repercussions of their acquired disability, all of the athletes addressed different positive opportunities that they perceived as directly resulting from their experience with trauma, thus further showing the presence of PTG in these athletes' lives.

"I think I've never would have had this opportunity, I never would have been competing at this level, had I not had the accident and that's something that really opened things up for me and like gave me a lot of opportunities [um] yeah. There are lots of things I've been able to do because of the accident, that I would have not been able to do yeah, it kind of opened doors in that respect." (Becky)

"If it hadn't happened, I wouldn't get to go to the Paralympics -- I got to do - do a lot of things since I lost my [appendages], that I would have not been able to do before, but at the same time you know, there are things that I used to do before that I would love to do again."(Anthony)

Becky perceives that she is competing at such a high level because of her accident. She keeps mentioning the actual event - the accident itself - as the reason, indicating that it was the disability resulting from the accident that produced these particular opportunities. Similarly, Anthony echoes this connection, such that he perceived that losing the [appendages] (e.g. amputation) enabled the new opportunities in his life. Thus, these participants' narrative emphasis on the actual impairment as the catalyst for the positive change is at odds with the general PTG position that PTG stems as a result of the struggle and not the event itself (Tedeschi et al., 2018). Furthermore, the participants accounts seem to place the body, at the centre of their experience, making the body a key element in facilitating their PTG. Finally, even though these athletes were athletic prior to their impairment, they all stated that they became more focused and sports-oriented after the trauma. This demonstrates corporeal-based action-focused growth in the behavioural achievement of moving from amateur to elite sporting positions as well as increased prioritisation on positive health behaviour changes (physical activity) (Hobfall et al., 2007). Taking a behavioural perspective of PTG has been cited as a way of adding to our understanding of the PTG field and can 'add validity' to the research area (Tedeschi et al., 2018; Shakespeare-Finch \& Barrington, 2012, p. 433).

Additionally, among these athletes, there seemed to be new awareness and appreciation of the sport in their lives as Becky describes below: 
"Getting to compete at the Paralympic level is something that (um) I mean I was very athletic as a youngster, but I wasn't driven into one specific particular sport. It's like when I was sixteen, seventeen I played so many sports. I wasn't brilliant at one, I was just very good at a lot, so like I wasn't driven to go to like Olympics - do you know what I mean - whereas the Paralympics, getting into [her sport] I loved that sport and it is a sport that I can do, so I had a drive for that one sport that I could do and I never would have gone - I was always very sporty - but I think I would have not gone down that path of sport as in that big of a deal in my life, I mean I would have not been a professional sports player or anything like that." (Becky)

Thus, in this specific population, the positive change following adversity is deemed to be achieving elite levels of athletic ability and high competition level- such that they are surpassing previous levels of sports functioning by competing at the Paralympic games. They attribute their trauma and the subsequent struggle as the catalyst for pushing them to become even better athletes than they were before the traumatic event occurred (Calhoun, Tedeschi, Cann \& Hanks, 2010).

\subsection{The Paralympics 2012- changing attitudes}

Acquired disability as a trauma signifies a massive change in a person's social position; identity as a social phenomenon becomes apparent as 'individuals are perceived by themselves and others as different' (Hogan, 1999, p. 80). These three athletes noticed an attitude change in the Paralympics 2012 as if the world had become more accepting towards disability sports. There was a sense of the games being parallel to the Olympics, being respected as athletes, and in some ways treated as superior because they had to overcome tremendous obstacles and they still competed at such a high level. For these athletes, the event itself was at the centre of their experience of PTG:

"I think the thing that always stuck with me, was just the general public, how much they got into it -- they were just so into the Paralympic games. I don't know if that was the ticketing and people could afford to go to the Paralympic games, so that was their chosen thing to do or...[stops the sentence] - I don't know if it was the advertising or ticketing or what made that happen, but it's, you think like you think back to Beijing, and they were shipping schools in to try to make it look busy on TV and yet we were selling out every day. It's [laughs] it's, something has changed somewhere, it's either the British concept of disabled sports or the world is changed, and it's more accepting now." (Caroline)

Although Caroline questioned the reasons behind people's attendance and the sold out stadiums, there is hope at the end of her sentence that the world is more accepting, which reveals the perceived need for the change. Similarly, Becky also felt supported at the Paralympics 2012 and furthermore, noted its possible superior nature compared to Olympics. She seems to express a sense of pride in being a Paralympian: 
"It was quite a unique experience and I am really glad that the Paralympics got as much support this time around as the Olympics 'cause I don't think in the years before it has had the same support, but I think this time it really kind of actually the Paralympics sport is just as amazing if not better than the Olympic sport because of what people have gone through like accident's or born with disabilities and they are still competing at a high level." (Becky)

And later...

"I felt really lifted by the crowd [um] and like yeah it really, really amazed me just like seeing the whole the - you know the UK coming to support (um) athletes, and that's the important stuff, they didn't come to support disabled athletes they came to support athletes, and when you were there you didn't feel disabled -nobody was disabled, everybody was just so - that you needed to compete in your sport, and when you are [competing], that disability isn't there the same way when you're off doing normal day things (um) yeah it was just incredible." (Becky)

Becky exhibited tremendous joy that the Paralympics were supported as much as the Olympics this time, for her it seemed to be vital that they were seen as athletes rather than disabled athletes. This uncovers the desire to be considered as a person first, rather than through the overpowering identity of 'disabled'. Furthermore, the experience of being admired and respected was an important experience for these athletes. This is a novel finding, as previous Paralympics had not been as successful as the London 2012, where many events were oversubscribed for the first time in Paralympic history (William, 2011). The Olympic games has always been more popular in various ways (money, audience, TV coverage, et cetera), however, for the first time in 2012, the Paralympics received an audience attendance close to Olympics. Thus, the attitude change that these athletes sensed could reflect a more significant shift in society, a step forward for social equality (DePauw, 1997).

\section{The Sport was, Sport is \& Sport will be}

All of the participants perceived that sport had always been an integral part of their lives and it was clear it would always be. Sport appeared to be the overarching aspect in these athletes' lives; reaching from life before the trauma to life as it was now and all the way to future goals. Sport was the platform of recovery, camaraderie, achievements and the base for their new identity as an athlete, bringing a sense of transcendence and equality into their lives; in sum, sport was an essential element of their experience and journey of PTG.

\subsection{I am an athlete}

Visible (physical) disability tends to produce an overpowering 'disabled identity' for the individual, shadowing other roles and identities that the person possesses (Charmaz, 
1995a;b). However, sport provided another identity for these individuals- that of an athlete. For these three, it was clear that the acquired disability was not the sole reason for their career and success in sports and should not be considered so. Their identity as athletes was related to the way they approached the job as individuals and athletes.

\begin{abstract}
"It's not-you don't sit there and worry about it [disability] and think you know every time you achieve something it's you know related to your disability or anything it's just you know you just want to be considered 'cause you're an athlete - You know your disability has got you into the sport that you do but after that it's - it's not you know - it's inconsequential it doesn't matter to the end goal or to the position you know, that you're in and in the sport that you are in the Paralympics and all that." (Anthony)
\end{abstract}

Anthony appears to describe frustration towards the disability status following him everywhere. He wants to be considered as an athlete, which reveals that the role of being disabled often overpowers other roles. He appears to want people to understand that being an athlete at this level takes more than a disability. However, he does seem to perceive benefitting mentally from dealing with the aftermath of the trauma of acquired disability and found it helpful in sports:

"I think from the sporting point of view as well 'cause a lot disabled athletes have done you know - you know done stuff like you know had to learn to walk again or faced a lot of random challenges and stuff and you're quite strong mentally -you can deal with you know setbacks and defeats and all that sort of thing I think a lot easier." (Anthony)

and further...

Yeah, I definitely think there is a mental toughness that comes with it you know the side of disability that doesn't get appreciated outside of sports." (Anthony)

Anthony's description gives a unique insight into positive consequences perceived as resulting from trauma. The feelings of pressure and disappointment are part of sports participation. Thus, learning effective coping skills for athletes is vital (Weinberg \& Gould, 2011). Mental toughness, according to Loehr (1995), is 'the ability to consistently perform towards the upper range of your talent and skills regardless of competitive circumstances' (p.5). This skill is considered desirable in a sporting environment, and has only recently been explored within the Paralympic athletics setting (Powell \& Myers, 2017). In the first exploratory qualitative design to explore the conceptualisation and development of mental toughness in Paralympians, Powells and Myers (2017) found that experiencing physical and mental challenges can help 'adaptive development of personal characteristics' (p.15), and argued that more was needed to explore this construct, especially within acquired disability. From the data presented here, it appeared that the athletes perceived gaining mental toughness through their traumatic 
experience, which may have created an advantage from going through something that is generally considered solely a negative experience. The development of positive change attributed to the struggle of impairment is more in line with PTG theory (Tedeschi et al., 2018) and develops the narrative discussed in Theme 1.2.

\subsection{The team as a resource}

Team sport was an essential part of the athletes' life. The team appeared to create surroundings that enabled these individuals to be their authentic selves. There was a strong sense of omnipresent humour that was an integral part of the team culture, and it almost appeared as a unique language that was a privilege of the insiders. Furthermore, similarities between previous experiences seemed to create a unique platform for cohesiveness; as a team, they were almost an extended family, a unit that offered anything from support to sharing practical ideas related to the injury. Becky reflects here:

"There is that kind of, you know, it's ok to laugh if that kind of thing happens [if somebody falls] every now and again and like just kind of make a joke about it and it's ok within that kind of safe environment. Like you would be pretty pissed off if somebody on the street laughed at you [laughing] - the people [in the team] are not going to make you feel like an idiot for falling over or make you feel uncomfortable that you fall over sometimes and I mean that can be quite nice so you know it's kind of ok to fall over, it's ok that, you know, you need a bit help to get back [up]-it's that comradeship, and you're around it [the team] so much as well you've become like a second family, you just kind of all surround each other (um) and you know after a while it's just easier to say things to people when you are around them all the time, yeah it just makes you feel more comfortable within yourself and we all do it for each other as well, just take the mickey out of each other." (Becky)

And Anthony also notes...

"You know, 'find a sport and carry on'; you know it's great the fact that mostmost of the guys here are amputees, everybody has been through the same things, so whether it's you know, 'why did you get that [fitting]?', 'what kind of [fitting] is that?' to you know dealing with limb fittings and that sort of things, you know it's quite good to chat to the people not so much for the support, but for like ideas and things, because somebody else has been through the same thing, it's good in that way as well." (Anthony)

This social support evident in the team culture was perceived to foster PTG for these athletes, and the literature supports this finding (Tedeschi et al., 1998; Hefferon et al., 2008; Sabiston et al., 2007). Additionally, for strong team cohesion, social support is vital (Weinberg \& Gould, 2011). Thus, athletes that have such a unique sameness of experiences could have significant advantages compared to teams where such a 
connection is not readily evident. Indeed a team has its distinctive features compared to other groups, one of them being its collective identity (Weinberg \& Gould, 2011). As a team, athletes with disabilities already possess a common ground and similarity of experiences and thus elements of effective team climate, e.g. social support, proximity, distinctiveness, fairness and similarity (Cartwright \& Zander, 1968; Eys \& Kim, 2017; Weinberg \& Gould, 2011).

\subsection{Being equal feeling equal}

The sporting environment itself seemed to have another essential meaning for the athletes as they all voiced a sense of equality relating to sports. Sport offered a setting where it was possible to compete at an equal level, thus the same set of skills were required from everybody whether you were non-disabled or had a disability. Furthermore, the athletes described situations where the disability was considered beneficial while playing the game. Here Anthony describes the importance of an even match situation, where everybody has the same baseline for the game, same opportunities to win and lose:

"I think it helps as well, the fact that you can't use your [appendages], everybody is in the same boat. Whether you're missing one [appendage], two [appendage], or you still got both, you still got to move, you know, in a similar kind of way, so everybody is in the same boat, so it's good in that way." (Anthony)

He then continues to explain how the disability can be an advantage:

"It's still the same sort of skill set you'll need, whether you are disabled or ablebodied. So anyway that's quite helpful because like when we play, a lot of the time some of the guys that we play against, you know, have no disability, so we find that actually, in some positions, having no [appendages] actually helps -- if you got any [appendages] they get in the way a bit, and it's hard to move -- So it's strange like in some ways it's an advantage in our game, you know, in certain positions -- it's quite a strange - quite a strange thing you know in sport, that being more disabled is an advantage. It's quite good, quite helpful." (Anthony)

Anthony's description of the disability as an advantage illuminates this perspective of different abilities, showing that the non-norm can be superior. The idea of different abilities connects to a common issue with disability being based on the medical model where ability is defined in relation to the non-disabled norm (Brittain, 2010; DePauw \& Gavron, 1995).

\section{The journey of the wounded body}

The acquired disability as an unexpected and permanent disability was an enormous trauma for these individuals and a disturbance of their body and self-image. These 
athletes' had to re-evaluate the role of the body in their identities. Creating a new relationship with their body was a key facilitator of psychological well-being and positive identity, thus an essential route to growth. These athletes described in their interviews a journey of PTG through their bodies, however, this journey was not linear; it was more complex, and the memory of the old body cohabited the new, changed body, thus being a constant reminder of the fragility and vulnerability of the physical self and yet also a source of appreciation for it.

\subsection{Frustration towards the new body, missing the old body}

There was a common theme among the athletes where they described being frustrated towards their new, changed body and how it did not work as it used to. These frustrations related quite often to the physical skills they had before the impairment. However, now in this new physical existence, they were struggling with some of these skills, which used to feel effortless and automatic. Caroline describes here a conflict between her mind and her body. The memory of the old body and how it used to work was lingering in her mind, almost not accepting that the body was not listening to her and doing what she knows it can do:

"I was just so frustrated and angry with myself, that I just slowly turned away from sports. I kept it out of my life to keep the frustration and anger away -- it was more knowing that you can do it, but physically not being able to do it, it's the frustrating bit for me." (Caroline)

The frustration frequently paired with memories of the body when it was at its best and even beyond, thus further contributing to the gap between old and new physical abilities, as Becky portrays here:

"'Cause I was kind of like, I liked running around and climbing trees and doing
sports and stuff like that, so I was a very active child, so I fell out of trees and
stuff all my own fault at the time and I like broke my arm and stuff like that, so
I went through various injuries when I was growing up, and I didn't mind being
injured, but I wanted to get back out and do things, and this is kind of like that
now, I don't mind that the injury happened so much, but now I am bothered
about the fact that it is restricting me so much with things that I want to do."
(Becky)

Here Becky describes a 'super body' of sorts that was falling off trees and on the move every hour of every day. This strong description illustrates how she remembers the old body was effortless, strong and recovered from anything and she was almost frustrated that the body that she used to know was not healing as before. Further, Anthony notes:

"Well, I admit it's quite frustrating anytime you try something new, that you can't do it instantly, it's a quite an annoying feeling ... but I think you know... 
The fact that you're doing a sport, you know, not just because you want to -well you do want to - but you're doing a new sport because you can't do the old one and especially the fact that you got to think is quite frustrating." (Anthony)

The frustration that Anthony is describing illustrates how he had been accustomed to using his body without thinking, almost as the body used to be automatic, effortless, and this frustration has is a common account from athletes who have been injured (Sparkes \& Smith, 2013). However, this new situation forced him to take notice of his corporeal self. Anthony's description illustrates how humans tend to live their lives without really noticing the body; it is often 'taken for granted' (Frank, 1995/2013; Leder, 1990). This heightened corporeal awareness paired with negotiating a new relationship with the physical self has been reported in previous studies (Smith \& Sparkes, 2013) and connects to the preliminary stages and experiences discussed within the working theory of Corporeal PTG (Hefferon et al., 2009; 2010; Hefferon, 2012; 2013).

\subsection{Rediscovering the body}

Following this frustration, the athletes went on to describe experiences where they recognised that their 'new body' was actually more capable than their original posttrauma assumptions. Learning new skills with their new body was an essential part of rediscovering their body's abilities, reconnecting them to their corporeal self and thus an important route to PTG.

"It [learning new skills] makes me feel good, yeah I know it's good to learn how to use things in a different way. Like you can still use your body differently, that's good 'cause (um) there is not so much that you learn to use differently, but you know yeah it is - it is quite nice to learn things differently and think 'oh actually I can still play this, or I can still do that even though I have this disability'." (Becky)

Becky was still discovering new and different abilities of her body-some of these abilities that she thought she had lost. Becky had started to reconnect with her new body. Similarly, Caroline contemplated the differences and similarities of the sport she previously played and the adapted version of it. She recognised that she needed to learn new skills in order to be able to excel in this new form of the sport:

"I looked at the two sports' and thought that they are very different. There are different components to them. So, I would have to learn new skills, and hopefully, that would take the frustration away and hopefully I had some kind of skill base there so that I could play (um). So, I came into it quite quickly and (um) caught up the people - that had been playing about six months more than me - very quickly." (Caroline) 
Here Caroline has found her way back to sports after almost removing it entirely from her life because of the frustration that she felt towards her new body (see 3.1). Learning new skills with her changed body removed the frustration, and she started to exhibit some pride in how quickly she learned her new sport. This rediscovering of the body's abilities and assets (focus on functionality), via the participation in sport/physical activity, was an important aspect in these athletes' experiences of PTG and again supports Hefferons (2012) Corporeal growth's concept of creating a 'new relationship with the body' (Hefferon et al., 2008; 2009; 2010) and the reconnection of the body-self (Sparkes \& Smith, 2013).

\subsection{Appreciating the new body}

For these athletes, the body that had once been - and at times still was - a source of frustration and a reminder of what was lost, also became a reminder of what they still had and even a source of accomplishments. Appreciation for the body that was before taken for granted and automatic (see 3.1) came from the realisation that it was breakable as well as capable of learning new skills (3.2) and in some ways, the wounded body became a symbol of relief and survival.

"I have more respect for it [the body] it is breakable [laughing] -- - I don't think respect is the right - right word, but I can't think of another word -- so I think I just have a better understanding of what my body can achieve and I try and push for centimetres rather than metres now." (Caroline)

Caroline here recounts how she was now able to understand her body and its limits, which was not always evident in her interaction with her previous physical self. There was also an element of looking at what her body can (capabilities) do versus its limitations, 'pushing for centimetres rather than metres'. She continues later on as to why she does not want to cover up the wounded part of her body:

"It's not for me to have it covered up, I-I don't care, it's if you could understand how much pain I was in for ten years, and just generally being grumpy and horrible, having that [pointing to the prosthesis] to me is a good thing. I'm not in pain and now I can live my life, so I don't care what it looks like [laughing] it could be really hideous and I still wouldn't care." (Caroline)

For Caroline, the prosthesis is a positive thing, a sort of patch of honour. Anthony also describes this "relief", and that the amputation was a positive thing for him, allowing him to move on and start living;

"Weirdly having my [appendages] cut off was a relief because it's, you know, they had to go and do fix operations, and it was cutting things off and putting things back on, [...] and it was painful as well -- Seems quite strange that having 
your [appendages] cut off was actually a good thing. Because, you know, it allowed me to move on -- as soon as you get fitted with prosthetics, there is not a lot you can't do you know -- it was a means to an end rather than just sort of you know 'oh my [appendages] are gone!' it's just 'oh you know, just take a false [appendage] on and let's just get on with stuff'." (Anthony)

Ultimately, for these athletes, the body was a constant, tangible reminder of what they have gone through, and thus an infinite source of appreciation of the body and life itself. The role of the body in reminding us of our mortality is a large area of research (Frank, 1995/2013; 1998; Lykins et al. 2007; Vail et al., 2012; Burke, Martens \& Faucher, 2010). However, the links to the body, trauma, and mortality salience has only recently been linked to positive growth and transformation following trauma (Hefferon et al., 2010; Gorven \& du Plessis, 2018; Vail et al., 2012; Cozzolino, 2006). Corporeal PTG posits that when an individual has undergone a physical trauma where the body has been permanently damaged or altered by an internal or external transgressor (thereby creating a permanent mortality salient environment), there may be unique processes and outcomes that the individual must go through in order to survive and eventually grow (Hefferon et al., 2008; 2009; 2010; Hefferon, 2012; 2013; 2018).

\section{Conclusion}

This study aimed to provide an in-depth account of the experience of posttraumatic growth in Paralympic athletes. This study accessed a unique and difficult to reach sample of athletes with disabilities who participated in the 2012 London Paralympics. The study found that elite sport was a fundamental route to experiencing PTG as well as an outcome in itself. It was part of the recovery, the foundation for camaraderie and a new identity as an athlete. Furthermore, sport was a source of achievement and future goals. Additionally, the team was seen as a resource, creating a safe environment in which to learn new skills and share practical ideas. These surroundings promoted a sense of equality among athletes. This knowledge contributes to the areas of sport and positive psychology by providing these unique insights to a niche population of elite athletes and their experience of posttraumatic growth.

The role of the body in facilitating PTG was another key finding in this study, thus providing further support for future exploration of embodied experiences within the PTG process and outcomes. The athletes experienced heightened corporeal awareness following their trauma, leading to a new relationship with their corporeal self. Although the wounded body was indeed frustrating to deal with after the trauma, the athletes found that rediscovering their physical and athletic capabilities through sport (albeit a different one) gave them a sense of psychological strength or "mental toughness" as per their account. They learned to appreciate their bodies more and the limitations and capabilities they possessed. The body was thus a reminder and an essential route to appreciating life and a sense of personal strength. The role of the body in PTG has only 
recently started to gain recognition in PTG research and thus this study contributes to a knowledge area that it is still in its infancy. These finding are impactful considering how central the body is for both athletes and individuals with physical impairment (AllenCollinson, 2009; 2017). The body and the corporeal experience was at the core of these athletes physical performance and the trauma of physical impairment. The findings from these elite athletes can have implications for rehabilitation processes and the facilitation of peak performance within elite athletics. For example, the results strongly support the inclusion of body functionality focused interventions in the aftermath of physical trauma, focusing on acceptance, locating strengths and appreciation of the body (Alleva et al., 2018).

Although physical activity has already been studied as a facilitator of PTG following physical trauma (Hefferon et al., 2008; Sabiston et al., 2007), this study suggests that elite structured sports may provide additional positive psychological outcomes beyond physical activity (Day, 2013). Future research could reflect upon the potential differences between the team (elite and leisure) and solo sports as many facets of sports, including belonging to a team, learning new skills and participating in a safe environment and experiencing personal achievements in sports, were perceived to be a route to recovery following trauma. Furthermore, researchers should ensure to encapsulate the entirety of the sport experience, including the distressing and sometimes pressurised environments the sporting context can create, in order to understand its impact from a holistic perspective (Caddick \& Smith, 2014; Day \& Wadey, 2016; 2017).

Finally, as there is currently discussion within the field regarding the construct and methodological designs utilised to understand PTG (see Jayawickreme \& Blackie, 2014), we support the call for more critical explorations into PTG and sport participation (Howells \& Fletcher, 2016; Day \& Wadey, 2017). Researchers are encouraged to employ more longitudinal, mixed method inquiry, as well as exploration across varying trauma types (e.g. direct or indirect) and contexts (e.g., acute, repeated, chronic, cumulative, physical), in addition to more embodied behavioural (action-focused) PTG perspectives.

\section{Considerations: Assessing Validity}

As qualitative research cannot be held to the traditional quantitative modes of quality assessment (e.g. replicability, etc.), there are several relatively agreed upon qualitative quality control criteria in which we can assess the validity of this study (Yardley, 2015; 2017): a) sensitivity to context (e.g. to participants experiences and environment; to the data by limiting deductive categorization, etc.); b) commitment and rigor (e.g. displaying in-depth knowledge regarding the area, the process and the methodology chosen; adhering to methodological principles; engaging in in-depth analyses); c) transparency and coherence (e.g. readers can see how the final data set was produced and the connections between themes, quotes presented and any interpretation offered); and d) impact and importance (e.g. 'useful' knowledge is produced... 'whether in terms of 
practical utility, generating hypotheses, or even changing how we think about the world' (Yardley, 2017, p. 296).

The current research adhered to the aforementioned quality criteria by: being aware of the participants context, as athletes with acquired disabilities, and conducting all interviews through the collaboration with team coaches as well within the familiar gym environment. Commitment and rigor were adhered to via the building of in-depth knowledge in the literature area, the choice of an appropriate methodology chosen based on research question, dearth of extant literature in topic area and participant pool. Furthermore, there was adherence to IPA as a methodology (versus a method) from question formulation through to write up; and an in-depth and detailed analyses, in which the $1^{\text {st }}$ author engaged in regular discussions with the second author regarding theme development. Finally, throughout the entire research process, the $1^{\text {st }}$ author engaged in reflexive practice via the use of a diary and note taking (Gough, 2017). Transparency and coherence are provided through the detailed methods section presented here (so as readers can understand the process) as well as clear presentation of the themes, quotes provided, and interpretation offered. In terms of impact of importance, the authors feel this research not only gives voice to a participant pool that has not adequately been represented in the literature, it offers first-hand account of the theory of Posttraumatic Growth within Paralympic elite athletes and furthers development of the working theory of Corporeal Posttraumatic growth in acquired disability, an area worth exploring within traumas where the body has been physically altered by an internal or external transgressor. We encourage researchers to examine more embodied perspectives of PTG through various methodological approaches and populations who have experienced physical illness and injury (Walsh et al., 2018).

\section{Authors}

Hanna Kampman

University of East London

H.M.K.Kampman@uel.ac.uk

Kate Hefferon

University of East London

k.hefferon@uel.ac.uk

\section{Publishing Timeline}

Received 30 August 2018

Accepted 16 November 2019

Published 1 February 2020

\section{References}

Acevedo, E. O. (2012). Exercise psychology: Understanding the mental health benefits of physical activity and the public health challenges of inactivity. The Oxford handbook of exercise psychology. London, UK: Oxford University Press.

Allen-Collinson, J. (2009). Sporting embodiment: Sports studies and the (continuing) promise of phenomenology. Qualitative Research in Sport and Exercise, 1(3), 279-296. 
Allen-Collinson, J. (2017). Breathing in life: Phenomenological perspectives on sport and exercise. In B. Smith and A. C. Sparkes (Eds), Routledge handbook of qualitative research in sport and exercise (pp. 1123). Oxon: Routledge.

Alleva, J. M., Martijn, C., Van Breukelen, G. J. P., Jansen, A., \& Karos, K. (2015). Expand your horizon: A programme that improves body image and reduces self-objectification by training women to focus on body functionality. Body Image, 15, 81-89.

American Psychiatric Association (2013). Diagnostic and statistical manual of mental disorders (5th ed.). Arlington, VA: American Psychiatric Association.

Biddle, S., Mutrie, N., \& Gorely, T. (2015). Psychology of physical activity: Determinants, well-being, and interventions ( $3^{\text {rd }}$ ed.). Abbingdon, Oxon: Routledge.

Bramley, N., \& Eatough, V. (2005). The experience of living with Parkinson's disease: An interpretative phenomenological analysis case study. Psychology E Health, 20(2), 223-235.

Brittain, I. (2010). The Paralympic Games explained. London, UK: Routledge.

Burke, B. L., Martens, A., \& Faucher, E. H. (2010). Two decades of terror management theory: A metaanalysis of mortality salience research. Personality and Social Psychology Review, 14(2), 155-195.

Caddick, N. \& Smith, B. (2014). The impact of sport and physical activity on the well-being of combat veterans: A systematic review. Psychology of Sport and Exercise, 15 (1), 9-18.

Calhoun, L. G., Tedeschi, R. G., Cann, A., \& Hanks, E. A. (2010). Positive outcomes following bereavement: Paths to posttraumatic growth. Psychologica Belgica, 50(1-2), 1-2.

Calhoun, L. G., \& Tedeschi, R. G. (2013). Posttraumatic growth in clinical practice. Routledge.

Carman, T. (2000). The body in Husserl and Merleau-Ponty. Philosophical Topics, 27(2), 205-226.

Cartwright, D. P., \& Zander. (1968). Group dynamics: Research and theory. NY, NY: Harper \& Row.

Charmaz, K. (1995a). Identity dilemmas of chronically ill men. In: D. F. Sabo and D. F. Gordon (Eds.), Research on men and masculinities series, Vol. 8. Men's health and illness: Gender, power, and the body (p. 266-291).

Charmaz, K. (1995b). The body, identity, and self. The Sociological Quarterly, 36(4), 657-680.

Chopko, B. A., Palmieri, P. A., \& Adams, R. E. (2018). Relationships among traumatic experiences, PTSD, and posttraumatic growth for police officers: A path analysis. Psychological Trauma: Theory, Research, Practice, and Policy, 10(2), 183-189.

Cordova, M. (2008). Facilitating posttraumatic growth following cancer. In S. Joseph \& A. Linley (Eds.), Trauma, recovery and growth: Positive psychological perspectives on posttraumatic stress (pp. 185-206). New York: John Wiley.

Cozzolino, P. J. (2006). Death contemplation, growth, and defense: Converging evidence of dualexistential systems? Psychological Inquiry, 17(4), 278-287.

Crawford, J. J., Gayman, A. M., \& Tracey, J. (2014). An examination of post-traumatic growth in Canadian and American ParaSport athletes with acquired spinal cord injury. Psychology of Sport and Exercise, 15(4), 399-406.

Day, M. C. (2013). The role of initial physical activity experiences in promoting posttraumatic growth in Paralympic athletes with an acquired disability. Disability Rehabilitation, 35(24), 2064-2072. https://doi.org/10.3109/09638288.2013.805822

Day, M.C. and Wadey, R., 2016. Narratives of trauma, recovery, and growth: The complex role of sport following acquired disability. Psychology of Sport and Exercise, 22, 131-138.

Day, M. C., \& Wadey, R. (2017). Researching growth following adversity in sport and exercise: Methodological implications and future recommendations. Qualitative Research in Sport, Exercise and Health, 1-15.

DePauw, K. P. (1997). The (In) visibility of DisAbility: Cultural contexts and "Sporting Bodies". Quest, 49(4), 416-430.

DePauw, K. P., \& Gavron, S. J. (1995). Disability and sport. Leeds, UK: Human Kinetics.

Desmond, D. M., Coffey, L., Gallagher, P., MacLachlan, M., Wegener, S. T., \& O'Keeffe, F. (2012). Limb Amputation. In: P. Kennedy (Ed.), The Oxford handbook of rehabilitation psychology (pp. 351-367). NY, NY: Oxford University Press.

Disability sport (2014). Sports Competitions for Disabled Athletes. Retrieved April 24, 2019, from 
http://www.disabilitysport.org.uk/sports-competitions-for-disabled-athletes.html

Dunn, D. S., Uswatte, G., \& Elliott, T. R. (2009). Happiness, resilience, and positive growth following physical disability: Issues for understanding, research, and therapeutic intervention. In: S. J. Lopez and C. R. Snyder (Eds.), Oxford handbook of positive psychology (2nd ed.) (pp. 651-664). NY, NY: Oxford University Press.

Dunn, D., Uswatte, G., Elliott, T., Lastres, A. \& Beard, B. (2014). A positive psychology of physical disability. In M. Wehmeyer (Ed). The Oxford handbook of positive psychology and disability (pp. 427-441). NY, NY: Oxford University Press.

Elliott, T. R., \& Kennedy, P. (2004). Treatment of depression following spinal cord injury: An evidencebased review. Rehabilitation Psychology, 49(2), 134-139.

Eatough, V., \& Smith, J. A. (2006). I feel like a scrambled egg in my head: An idiographic case study of meaning making and anger using interpretative phenomenological analysis. Psychology and Psychotherapy: Theory, Research and Practice, 79(1), 115-135.

Eys, M., \& Kim, J. (2017). Team building and group cohesion in the context of sport and performance psychology. In E. Acevedo (Ed.), Oxford encyclopedia of sport, exercise, and performance psychology. NY, NY: Oxford University Press.

Faulkner, G., Hefferon, K., \& Mutrie, N. (2015). Putting positive psychology into motion through physical activity. In: S. Joseph (Ed.) Positive Psychology in Practice. (2nd ed.) (pp. 207-222). Hoboken: Wiley.

Faulkner, G. E. J., \& Taylor, A. H. (2005). Exercise, health, and mental health: Emerging Relationships. London, UK: Routledge.

Fox, K. R., Biddle, S., \& Boutcher, S. (2001). Physical activity and psychological well-being. London, UK: Routledge.

Frank, A. W. (1995/2013). The wounded storyteller: Body, illness, and ethics. Chicago, USA: The University of Chicago Press.

Goldenberg, J. L., Pyszczynski, T., Greenberg, J., Solomon, S., Kluck, B., and Cornwell, R. (2001). I am not an animal: Mortality salience, disgust, and the denial of human creatureliness. Journal of Experimental Psychology, 130, 427-435.

Gough, B. (2017). Reflexivity in qualitative psychological research. The Journal of Positive Psychology, 12(3), $311-312$.

Grabe, S., Cook, A., Routledge, C., Anderson, C. and Arndt, J. (2005). In defence of the body: The effect of mortality salience on female body objectification. Psychology of Women Quarterly, 29, 33-7.

Griffiths, H., \& Kennedy, P. (2012). Continuing with life as normal: Positive psychological outcomes following spinal cord injury. Topics in Spinal Cord Injury Rehabilitation, 18(3), 241-252.

Gorven, A., \& du Plessis, L. (2018). Corporeal posttraumatic growth as a result of breast cancer: An interpretative phenomenological analysis. Journal of Humanistic Psychology, 0022167818761997. https://doi.org/10.1177/0022167818761997

Hammer, C., Podlog, L., Wadey, R., Galli, N., Forber-Pratt, A. J., Newton, M., Hall., M \& Greviskes, L. (2019). Understanding posttraumatic growth of paratriathletes with acquired disability. Disability and Rehabilitation, 41(6), 674-682.

Hargreaves, J. (2001). Heroines of sport: The politics of difference and identity. London, UK: Routledge.

Hartie, K., Smith, J. (2016). Five fathers' experience of an adult son sustaining a cervical spinal cord injury: An interpretative phenomenological analysis. Spinal Cord Series and Cases, 2, 16015 doi:10.1038/scsandc.2016.15

Hefferon, K. (2012). Bringing back the body into positive psychology: The theory of corporeal posttraumatic growth in breast cancer survivorship. Psychology, 3(12A), 1238-1242.

Hefferon, K. (2013). Positive psychology and the body: The somatopsychic side to flourishing. London, UK: McGraw-Hill Education.

Hefferon, K., Ashfield, A., Waters, L., \& Synard, J. (2017). Understanding optimal human functioning: The 'call for qual' in exploring human flourishing and well-being. The Journal of Positive Psychology, 12 , 3, 211-219.

Hefferon, K., Grealy, M., \& Mutrie, N. (2008). The perceived influence of an exercise class intervention on 
the process and outcomes of post-traumatic growth. Mental Health and Physical Activity, 1(1), 32-39.

Hefferon, K., Grealy, M., \& Mutrie, N. (2009). Post-traumatic growth and life threatening physical illness: A systematic review of the qualitative literature. British Journal of Health Psychology, 14(2), 343-378.

Hefferon, K., Grealy, M., \& Mutrie, N. (2010). Transforming from cocoon to butterfly: The potential role of the body in the process of posttraumatic growth. Journal of Humanistic Psychology, 50(2), $224-247$.

Hefferon, K. (2018a). From Birth to death: Living the embodied life. Keynote Address to the Canadian Positive Psychology Conference, Toronto, Ontario, May 2018.

Hefferon, K. (2018b). Celebrating complexity: The turn to qualitative research in positive psychology. Keynote address to the European Positive Psychology Conference, Budapest, Hungary, June 2018.

Hefferon, K., Mallery, R., Gay, C., \& Elliott, S. (2013). 'Leave all the troubles of the outside world': a qualitative study on the binary benefits of 'Boxercise' for individuals with mental health difficulties. Qualitative Research in Sport, Exercise and Health, 5(1), 80-102.

Hobfoll, S. E., Hall, B. J., Canetti-Nisim, D., Galea, S., Johnson, R. J., \& Palmieri, P. A. (2007). Refining our understanding of traumatic growth in the face of terrorism: Moving from meaning cognitions to doing what is meaningful. Applied Psychology, 56(3), 345-366.

Hogan, A. (1999). Carving out a space to act: Acquired impairment and contested identity. In: M. Corker \& S. French (Eds.), Disability discourse. Philadelphia, PA: Open University Press.

Howells, K., \& Fletcher, D. (2016). Adversarial growth in Olympic swimmers: Constructive reality or illusory self-deception? Journal of Sport and Exercise Psychology, 38(2), 173-186.

Howe, D. (2011). Sociology. In: Y.C. Vanlandewijck and W.R. Thompson (Eds.), The Paralympic athlete: Handbook of sports medicine and science. (pp.102-115). Chichester, Sussex: Wiley-Blackwell.

Ivtzan, I., Lomas, T., Hefferon, K., \& Worth, P. (2015). Second wave positive psychology: Embracing the dark side of life. London, UK: Routledge.

Leder, D. (1990). The absent body. Chicago, USA: University of Chicago Press.

Jayawickreme, E., \& Blackie, L. E. (2014). Post-traumatic growth as positive personality change: Evidence, controversies and future directions. European Journal of Personality, 28(4), 312-331.

Joseph, S. (2012). What doesn't kill us. London, UK: Piatkus.

Kampman, H., Hefferon, K., Wilson, M., \& Beale, J. (2015). "I can do things now that people thought were impossible, actually, things that I thought were impossible": A meta-synthesis of the qualitative findings on posttraumatic growth and severe physical injury. Canadian Psychology/Psychologie Canadienne, 56(3), 283-294.

Karanci, A. N., Işıklı, S., Aker, A. T., Gül, E. İ., Erkan, B. B., Özkol, H., \& Güzel, H. Y. (2012). Personality, posttraumatic stress and trauma type: Factors contributing to posttraumatic growth and its domains in a Turkish community sample. European Journal of Psychotraumatology, 3(1), 17303.

Kılıç, C., Magruder, K. M., \& Koryürek, M. M. (2016). Does trauma type relate to posttraumatic growth after war? A pilot study of young Iraqi war survivors living in Turkey. Transcultural Psychiatry, 53(1), 110-123.

Kira, I. A., Aboumediene, S., Ashby, J. S., Odenat, L., Mohanesh, J., \& Alamia, H. (2013). The dynamics of posttraumatic growth across different trauma types in a Palestinian sample. Journal of Loss and Trauma, 18(2), 120-139.

Lambert, L., D'Cruz, A., Schlatter, M., \& Barron, F. (2016). Using physical activity to tackle depression: The neglected positive psychology intervention. Middle East Journal of Positive Psychology, 2(1), $42-60$.

Loehr, J. E. (1995). The new toughness training for sports. NY, NY: Plume.

Lucas, R. E. (2007a). Adaptation and the set-point model of subjective well-being. Current Directions in Psychological Science, 16(2), 75-79.

Lucas, R. E. (2007b). Long-term disability is associated with lasting changes in subjective well-being: Evidence from two nationally representative longitudinal studies. Journal of Personality and Social Psychology, 92(4), 717-730.

Lykins, E. L., Segerstrom, S. C., Averill, A. J., Evans, D. R., \& Kemeny, M. E. (2007). Goal shifts following reminders of mortality: Reconciling posttraumatic growth and terror management theory. Personality and Social Psychology Bulletin, 33(8), 1088-1099.

Marini, I., \& Stebnicki, M. A. (2012). The psychological and social impact of illness and disability (6th ed.). New 
York, NY, US: Springer Publishing.

Martin Ginis, K. A., Bassett-Gunter, R. L., \& Conlin, C. (2012). Body image and exercise. In: A. Acevedo (Ed.), Oxford handbook of exercise psychology. London, UK: Oxford University Press.

Menzel, J. E., \& Levine, M. P. (2011). Embodying experiences and the promotion of positive body image: The example of competitive athletics. In: R. M. Calogero, S. Tantleff-Dunn, \& J. K. Thompson (Eds.), Self-objectification in women: Causes, consequences, and counteractions (p. 163-186). Washington, DC: American Psychological Association.

Merleau-Ponty, M. (2003). The phenomenology of perception. London, UK: Routledge.

Nizza, I. E., Smith, J. A., \& Kirkham, J. A. (2018). 'Put the illness in a box': A longitudinal interpretative phenomenological analysis of changes in a sufferer's pictorial representations of pain following participation in a pain management programme. British Journal of Pain, 12(3), 163-170.

Penedo, F. J., \& Dahn, J. R. (2005). Exercise and well-being: A review of mental and physical health benefits associated with physical activity. Current Opinion in Psychiatry, 18(2), 189-193.

Perridge, D., Hefferon, K., Lomas, T., \& Ivtzan, I. (2017). "I feel I can live every minute if I choose to": participants' experience of a positive mindfulness programme. Qualitative Research in Psychology, 14(4), 482-504.

Powell, A. J., \& Myers, T. D. (2017). Developing mental toughness: Lessons from Paralympians. Frontiers in Psychology, 8, 1270.

Reid, K., Flowers, P., \& Larkin, M. (2005). Exploring lived experience. The Psychologist, 18(1), 20-23.

Ryff, C. D., \& Keyes, C. L. M. (1995). The structure of psychological well-being revisited. Journal of Personality and Social Psychology, 69(4), 719.

Sabiston, C. M., McDonough, M. H., \& Crocker, P. R. (2007). Psychosocial experiences of breast cancer survivors involved in a dragon boat program: Exploring links to positive psychological growth. Journal of Sport and Exercise Psychology, 29(4), 419-438.

Shakespeare-Finch, J., \& Armstrong, D. (2010). Trauma type and posttrauma outcomes: Differences between survivors of motor vehicle accidents, sexual assault, and bereavement. Journal of Loss and Trauma, 15(2), 69-82.

Shakespeare-Finch, J., \& Barrington, A. J. (2012). Behavioural changes add validity to the construct of posttraumatic growth. Journal of Traumatic Stress, 25(4), 433-439.

Shirazipour, C. H., Meehan, M., \& Latimer-Cheung, A. E. (2017). An analysis of BBC television coverage of the 2014 Invictus Games. Adapted Physical Activity Quarterly, 34(1), 33-54.

Shuwiekh, H., Kira, I. A., \& Ashby, J. S. (2018). What are the personality and trauma dynamics that contribute to posttraumatic growth? International Journal of Stress Management, 25(2), 181- 194.

Smith, J. A. (2017). Interpretative phenomenological analysis: Getting at lived experience. The Journal of Positive Psychology, 12(3), 303-304.

Smith, J., Larkin, M., \& Flowers, P. (2009). Interpretative phenomenological analysis: Theory, method and research. London, UK: Sage Publications.

Smith, J. A. (2011). Evaluating the contribution of interpretative phenomenological analysis. Health Psychology Review, 5(1), 9-27.

Sparkes, A.C. \& Smith, B. (2013). Spinal cord injury, sport and the narrative possibilities of posttraumatic growth. In: N. Warren and L. Manderson (Eds.), Reframing disability and quality of life: A global perspective. (pp. 129-144). NY, NY: Springer.

Taylor, A. H., Cable, N. T., Faulkner, G., Hillsdon, M., Narici, M., \& Van Der, B. (2004). Physical activity and older adults: A review of health benefits and the effectiveness of interventions. Journal of Sports Sciences, 22(8), 703-725.

Tedeschi, R. G., \& Calhoun, L. G. (1996). The Posttraumatic Growth Inventory: Measuring the positive legacy of trauma. Journal of Traumatic Stress, 9(3), 455-471.

Tedeschi, R. G., \& Calhoun, L. G. (2004). Posttraumatic Growth: Conceptual foundations and empirical evidence. Psychological Inquiry, 15(1), 1-18.

Tedeschi, R. G., Cann, A., Taku, K., Senol-Durak, E., \& Calhoun, L. G. (2017). The posttraumatic growth inventory: A revision integrating existential and spiritual change. Journal of Traumatic Stress, 30(1), 11-18. 
Tedeschi, R. G., Park, C. L., \& Calhoun, L. G. (1998). Posttraumatic growth: Positive changes in the aftermath of crisis. London, UK: Routledge.

Tedeschi, R. G., Shakespeare-Finch, J., Taku, K., \& Calhoun, L. G. (2018). Posttraumatic growth: Theory, research and applications. NY, NY: Routledge.

Vail, K. E., Juhl, J., Arndt, J., Vess, M., Routledge, C., \& Rutjens, B. T. (2012). When death is good for life: Considering the positive trajectories of terror management. Personality and Social Psychology Review, 16(4), 303-329.

Vanlandewijck, Y., \& Thompson, W. R. (2011). The Paralympic athlete: Handbook of sports medicine and science. Chichester, Sussex: Wiley-Blackwell.

Walsh, D. M., Groarke, A. M., Morrison, T. G., Durkan, G., Rogers, E., \& Sullivan, F. J. (2018). Measuring a new facet of post-traumatic growth: Development of a scale of physical post-traumatic growth in men with prostate cancer. PloS one, 13(4), e0195992.

Walsh, D. M., Morrison, T. G., Conway, R. J., Rogers, E., Sullivan, F. J., \& Groarke, A. (2018). A model to predict psychological-and health-related adjustment in men with prostate Cancer: the role of post traumatic growth, physical post traumatic growth, resilience and mindfulness. Frontiers in Psychology, 9, 136.

Wankel, L. M., \& Berger, B. G. (1990). The psychological and social benefits of sport and physical activity. Journal of Leisure Research, 22, 167-182.

Weinberg, R. S., \& Gould, D. (2011). Foundations of sport and exercise psychology (5th ed.). Leeds, UK: Human Kinetics.

Wehmeyer, M. (2014). Beyond Pathology: Positive psychology and disability. In: M.Wehmeyer (Ed), The Oxford handbook of positive psychology and disability. (pp. 3-6). Oxford: Oxford University Press.

William, H. (2011, September 27). Paralympics events sell out for first time. The Independent. Retrieved from http://www.independent.co.uk/sport/olympics/paralympics-events-sell-out-for-first-time2361555.html

Wright, B. A. (1983). Physical disability - a psychosocial approach (2nd ed.). London, UK: Harper \& Row.

Wu, X., Kaminga, A. C., Dai, W., Deng, J., Wang, Z., Pan, X., \& Liu, A. (2019). The prevalence of moderate-to-high posttraumatic growth: A systematic review and meta-analysis. Journal of Affective Disorders, 243, 408-415.

Yardley, L. (2015). Demonstrating validity in qualitative psychology. In: J. Smith (Ed.), Qualitative psychology: A practical guide to research methods ( $3^{\text {rd }}$ ed.). London, UK: Sage Publications.

Yardley, L. (2017). Demonstrating validity of qualitative research. The Journal of Positive Psychology, 12(3), 295-296. 